\title{
Characteristic Behaviour of Aluminium Metal Matrix Composites: A Review
}

\author{
Prasanna Nagasai Bellamkonda ${ }^{1}$, Srikanth Sudabathula ${ }^{2}$ \\ ${ }^{1} \mathrm{PG}$ Student, ${ }^{2}$ Assistant Professor \\ Department of Mechanical Engineering, Gudlavalleru Engineering College, \\ Gudlavalleru, Krishna District, Andhra Pradesh, India
}

\begin{abstract}
This paper presents a summary of work reported on Aluminium metal matrix composites with different reinforcements. Aluminium metal matrix has growing demand in aircraft, automotive and other industries due to its light weight, high strength to weight ratio, corrosion resistance and workability. The work is done by reviewed of research Papers, Articles, Magazines, references books etc. The present work focus on mechanical properties and surface texture of aluminum matrix composites (AMCs) reinforced by silicon carbide, fly ash, $\mathrm{TiO} 2$, graphene and $\mathrm{B} 4 \mathrm{C}$ and with different wt\% by using stir casting technique. Each reinforced material has an individual property which when added improves the properties of the base alloy. Effect of different reinforcement on AMCs on the microstructure analyses and mechanical properties like tensile strength, hardness, density, electrical resistivity and wear behaviour is also discussed in detail. Major applications of different AMCs are also highlighted in this work.
\end{abstract}

Keyword: Aluminium metal matrix composites; Stir casting; Reinforcement; Characterization

\section{INTRODUCTION}

The metal matrix composites are combinations of two or more different materials with at least one being a metal and another material such as a ceramics or organic compound. When at least three materials are present it is called Hybrid composites. To achieve optimum combination of properties in composites. Three decades of intensive materials research have provided a wealth of new scientific innovation to synthesize special materials with enhanced efficiency with low manufacturing cost to fulfill the long Pending demands of the engineering sector. A new system of materials containing hard particulates embedded in a metal matrix have exhibited superior operating performance and improved tribological behaviors. Among MMCs, aluminium alloy based composites had shown the significant improvement in the mechanical, thermal, and electrical and wear properties to cater the demand of the industries. Among MMCs, aluminium alloy based composites had shown the significant improvement in the mechanical, thermal, electrical and wear properties to cater the demand of the industries. Al alloys are termed as versatile materials to be used for numerous engineering applications because of its better machining, joining and process ability. In addition to this, low cost, increased strength to weight ratio and other environmental friendly characteristics of $\mathrm{Al}$ alloys make them a preferable material in engineering applications [1]. Among the aluminium alloys, Al-Si alloy is well known casting alloy having high wear resistance, low thermal expansion coefficient, good corrosion resistance with improved mechanical properties over a wide range of temperatures. The grain refiner elements modify the $\mathrm{Si}$ morphology from coarse to lamellar (fine), thus enhancing the mechanical properties [2]. Different researcher developed numerous composite materials by using different type of matrix, reinforcement size, shape and volume as well as suitable processing technique depending upon the requirement and application. In order to achieve the optimum properties of the metal matrix composite, the distribution of the second phase in the matrix alloy must be uniform, and the wettability or bonding between these substances should be optimized. [3]. Rao and Das [4] prepared cast aluminium-alumina composites by incorporating 
alumina particles while stirring the molten alloy with an impeller. The particles Are added in the molten metal during mixing and thus the process of stir casting emerged. In addition to this mixing of nonwetting particles into alloys was promoted by addition of alloying elements such as magnesium during the composite synthesis.

\section{STIR CASTING}

Stir casting technique is simple and the most commercial method of production of metal matrix composites. In preparing metal matrix composites by the stir casting method, there are several factors that need to be considered [5], including:

1. Difficulty in uniform distribution of the reinforcement material.

2. Wettability between the two main substances.

3. Porosity in the cast metal matrix composites, and

4. Chemical reactions between the reinforcement material and the matrix alloy.

In conventional stir casting method, reinforced particulate is mixed into the aluminium melt by mechanical stirring. Mechanical stirring is the most important element of this process. After the mechanical mixing, the molten metal is directly transferred to a shaped mould prior to complete solidification. The essential thing is to create the good wetting between particulate reinforcement and aluminium melt. The distribution of the reinforcement in the final solid depends on the wetting condition of the reinforcement with the melt, relative density, rate of solidification etc. Distribution of reinforcement depends on the geometry of the stirrer, melt temperature and the position of the stirrer in the melt. Figure 1 shows a schematic diagram of stir casting process. An improvement in conventional stir casting is a double stir casting method or two-step casting process. In the first stage, the matrix material is heated to above its liquidus temperature and then cooled down to a temperature to keep in a semi-solid state. At this stage, the preheated reinforcement materials are added and mixed with a mechanical stirrer. Again the slurry is heated to a liquidus state and mixed thoroughly. Nowadays, this two-step mixing process has used in the fabrication of aluminium because of more uniform microstructure as compared of conventional stirring [6].

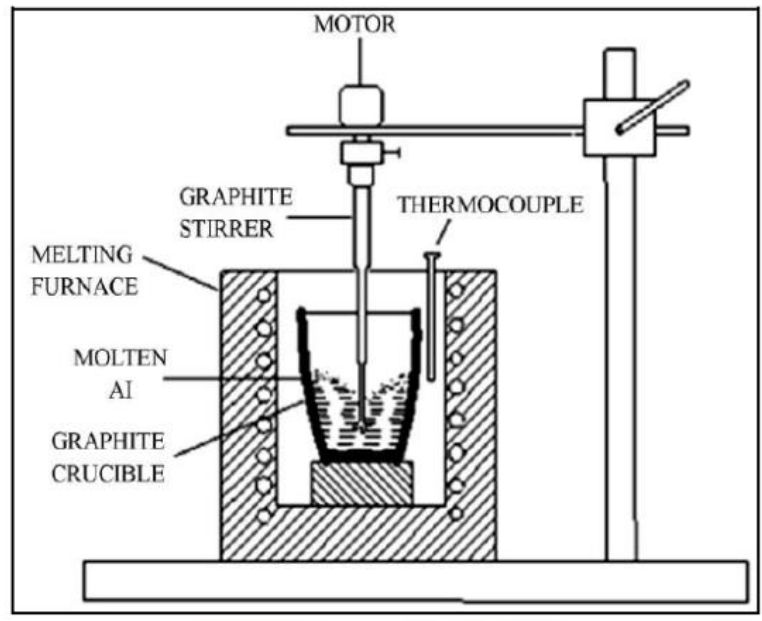

Fig.1. Stir Casting Process

A recent development in stir casting is three step stir casting for the fabrication of nanoparticle reinforced composite. In this method, first, the $\mathrm{Al}$ particles and reinforcement are mixed using ball milling process to break down the initial clustering of nanoparticles. Then the composite powder is mixed with melt by mechanical stirring [7].

\section{SILICON CARBIDE REINFORCED AMC}

Balasivanandha Prabu et al. [8]: Studied that better stir process and stir time the content of silicon in aluminium alloy is high Al-silicon carbide MMC material with $10 \%$ of silicon carbide by using a varying stirring speed and time. The scanning electron microscope (SEM) and optical microscope was used for examine the microstructure of composites. The various effects on microstructure and strength have been studied due to stirring speed and time. By increase in stirring speed and time resulted in uniform distribution of particles, the mechanical properties hardness of composites is also affected by stirring speed and stirring time. The most uniform value of hardness was achieved at $580 \mathrm{rpm}$ with $12 \mathrm{~min}$. stirring. Above this speed the properties decreases again.

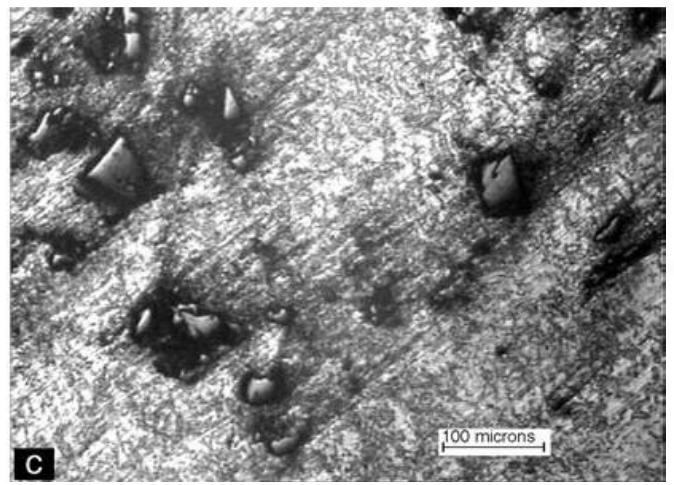

Fig.2. Microstructure of Al-10\%SiCp MMC fabricated at $580 \mathrm{rpm}$ : (a) $15 \mathrm{~min}$ stirring. 
Alaneme \& Aluko et al [9]: Has Pay attention on double stir-casting technique to cast the Al (6063) scrape and $\mathrm{SiC}$ and reinforcements of $\mathrm{SiC}$ in $3,6.1$, 9.2 and $12 \%$ volume into the furnace. And melt at temperature $750^{\circ} \mathrm{C}$. Then molten metal allowed to cool at $580^{\circ} \mathrm{C}$. They found this stage dehydrated borax mixture and silicon carbide was added into the molten metal and stirred for 15-20 minutes. Dora Siva Prasad et al. [10]: Studied that hybrid metal matrix composites with up to $8 \%$ rice husk ash and silicon carbide particles could be manufactured by using double stir casting process. The matrix showed uniform distribution of rice husk ash and SiC. With the increase of reinforcement percentage hardness and porosity also increases but density decrease with increase in rice husk ash and $\mathrm{SiC}$ content the yield strength and ultimate tensile strength increases. The most significant property of aluminium silicon carbide composites with aerospace industries is its strength to weight ratio, which is 3 times greater than mild steel. Fig. $3 \mathrm{a}$ and $\mathrm{b}$ shows the scanning electron micrographs of RHA and SiC sample. It could be observed that the rice husk ash consists of particulates with different sizes and different shapes. The average sizes of the rice husk ash and $\mathrm{SiC}$ samples were found to be $25 \mu \mathrm{m}$ and $35 \mu \mathrm{m}$, respectively.

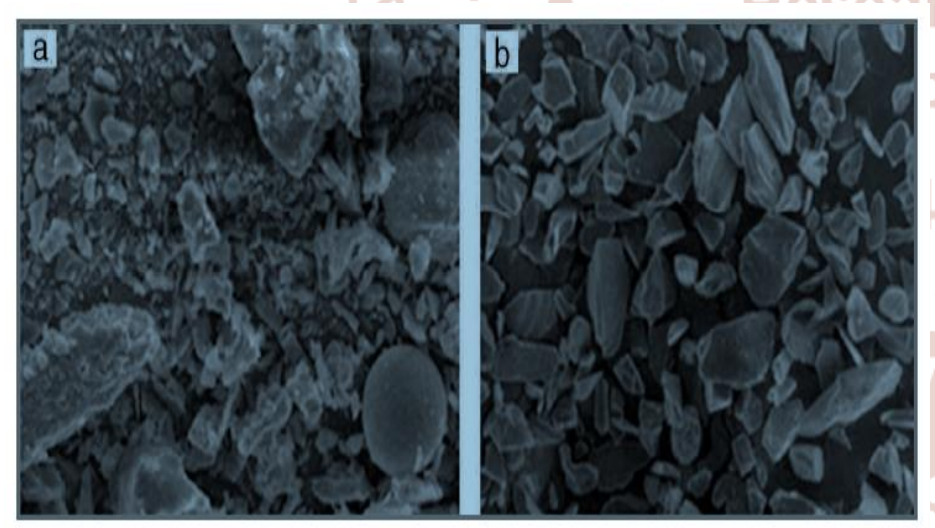

Fig. 3 - Scanning electron micrographs of (a) rice husk ash sample and (b) SiC particulates.

M. Gopi Krishna et al. [11]: Observed the deformation behavior of hybrid composites with aluminium matrix A2024 Alloy, reinforced with silicon carbide (Sic) and Fly ash. The hybrid particles are well dispersed in the matrix. The circumferential stress component $\sigma_{\theta}$ increasingly becomes tensile with continued deformation. Further an increase in aspect ratio from 1.0 to 1.5; the load required gets reduced for the same amount of deformation. For a fixed diameter, a shorter specimen will require a greater axial force to produce the same percentage of reduction in height. Friction factor ' $\mathrm{m}$ ' was determined experimentally for given set of dies. FEA modeling and analysis was successfully performed from the experimentally obtained friction factor values. Martin et al. [12]: investigated the Wear resistance in the temperature range $20-200{ }^{\circ} \mathrm{C}$. The addition of the $\mathrm{SiC}$ particulates improved the wear resistance by a factor of two in the mild wear region, and the transition temperature was raised by approx. $50{ }^{\circ} \mathrm{C}$. This higher transition temperature was due to the retention of the mechanical properties in the composite at elevated temperature. Heat treatments (either natural or artificial aging) did not modify substantially the wear resistance of either the composite or the unreinforced alloy. Aqida et al. [13]: investigated Porosity content at different speeds. Low speed of $100 \mathrm{rpm}$ tempted the clustered particles to enhance the porosity formation. Uniform distribution of particles was observed at the speed of 200rpm with less porosity. Higher porosity due to the entrapment of gas occurred at 500rpm. The higher content of silicon carbide increased the porosity volume. Bindumadhavan et al. [14]: Studied the Hardness, Wear resistance, the hardness of the composite increased with the SiCp content which also reduced the wear loss. For the same total volume fraction of $\mathrm{SiC}$ reinforcement the composite with small sized particles displayed better wear resistance as compared to the large sized particles composite. Dual Particle Sized (DPS) composites have potential for their material properties to be suitably altered to meet different engineering requirements by a suitable choice of particle sizes. Rodriguez et al. [15]: Reported that Wear behaviour at different pressures and temperatures. At a transition temperature, the wear rate changed from mild to severe wear for both the composites. The $\mathrm{SiC}$ reinforcement addition successfully shifted the transition temperature to higher values which were also dependant on pressure. It has been also observed that the presence of mechanically mixed layers on the wear surface with varying morphology and thickness seemed to be a key factor controlling the mild wear of these materials. Rao and Das et al. [16]: Reported that Effect of heat treatment on the sliding wear with applied load and sliding speed. The uniform distribution of SiC particles in aluminium alloy matrix was observed and the dendrites of $\mathrm{Al}$ and precipitates along the interdendritic regions were present. The maximum hardness was obtained at the peak aging $6 \mathrm{~h}$ of heat treatment and wear rate increased with increasing sliding speed and load. 
Addition of $\mathrm{SiC}$ particle increased the seizure pressure and temperature. Kaur et al. [17]: Investigated the Wear rate under different loading conditions and at various temperatures. The change in wear mechanism was observed with the increase in applied load. The $\mathrm{SiC}$ reinforced composites exhibited better wear resistant than unreinforced alloy even at higher loads due to the oxidative-cum-adhesive wear mechanism.

\section{Fly ash Reinforced AMC}

Fly ash particles are potential discontinuous dispersoids used in metal matrix composites due to their low cost and low density reinforcement which are available in large quantities as a waste by product in thermal power plants. The major constituents of fly ash are $\mathrm{SiO}_{2}, \mathrm{Al}_{2} \mathrm{O}_{3}$ and $\mathrm{Fe}_{2} \mathrm{O}_{3}$. Vipin K. Sharma et al. [18]: Reported that Aluminium fly ash composites were prepared by using stir casting process with different weight $\%(2,4$ and 6$)$ of reinforcement particles. fly ash contents are successfully used to fabricate the aluminium matrix composite. The optical microstructure of the composites indicates the distribution of the fly ash components throughout the aluminium matrix. The wear resistance of the fabricated composites increases with the increase in the fly ash contents. The composites with high fly ash contents resulted in $13.6 \%$ less wear as compared to low fly ash content composites. The sample with medium fly ash content (4\%) resulted in the lowest average coefficient of friction (0.12) and sample with high fly ash contents $(6 \%)$ shows the maximum average coefficient of friction (0.161). So the amount of fly ash contents in the aluminium matrix is limited to $4 \%$. More addition of fly ash contents tends to increase the coefficient of friction between the tribopairs. David Raja Selvam et al. [19]: Studied the microstructure and mechanical properties of $\mathrm{Al} \mathrm{SiC}$ Fly ash composites were produced by modified stir cast route with different weight percentage (viz 7.5 wt. $\%$ of FA and varying weight percentage 7.5 and $10 \mathrm{wt} . \%$ of $\mathrm{SiC}$ ) of reinforcement. The SEM micrographs revealed the presence of $\mathrm{SiC}$ and FA particles in the composite with homogeneous dispersion. The micro and macro hardness of the composites were increased from $69.53 \mathrm{HV}$ to $78.8 \mathrm{HV}$ and 49.4 BHN to 57.21 BHN with respect to addition of weight percentage of $\mathrm{SiC}$ and constant weight Percentage of FA particles. The reinforcement of particles has enhanced the tensile strength of aluminum matrix and composites From $173 \mathrm{MPa}$ to 213 Mpa.

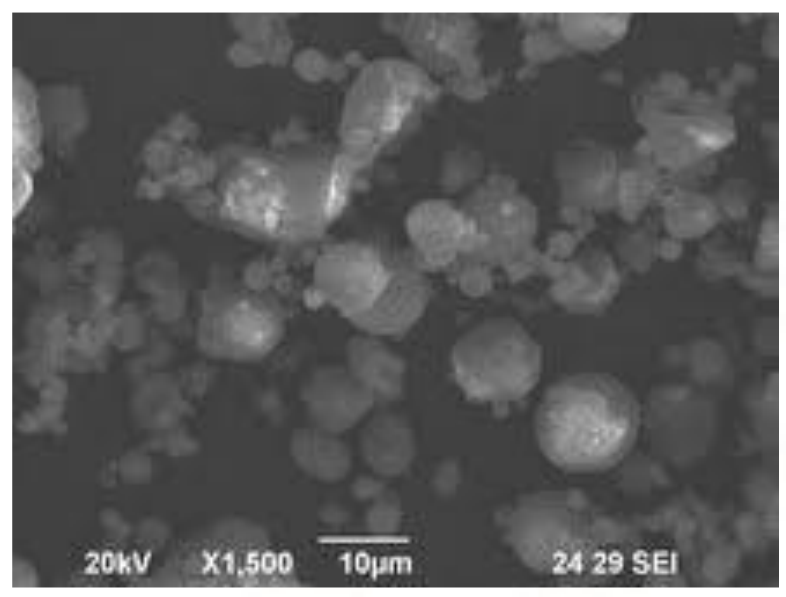

Fig.4. Microstructure of fly ash

Viney kumar et al. [20]: Studied about comparison of mechanical properties of two metal matrix composites have been investigated. In first case AL6061, 4\% MG chosen as a base metal and varying composition of Fly ash i.e. $10 \%, 15 \%$ and $20 \%$ was taken as reinforcement in second case AL6061, 4\% MG, $4 \%$ Graphite was taken as base material and varying composition of Fly ash i.e. $10 \%, 15 \%$ and $20 \%$ as reinforcement. It was found that tensile strength increase with addition of fly ash. Similarly when graphite was added then a decrease in tensile and hardness was observed. The composite with $4 \% \mathrm{Mg}$, $15 \%$ Fly ash found to be maximum tensile whereas composite of $4 \% \mathrm{Mg}, 20 \%$ Fly ash was found to be of maximum hardness. Specific wear rate decreases with addition of fly ash up to a certain volume whereas with graphite addition it also decreases. Shivaprakash et al. [21]: Studied the Hardness, Wear mechanism by performing the wear test by varying the speeds and by applying different normal loads. The increase of fly ash content increased the matrix hardness which in turn enhanced the wear resistance of the composite as compared to the unreinforced alloy. The filler volume was optimized between 23 to $35 \%$ which can provide the maximum wear resistance to the composite. Zuoyong Dou et al. [22]: studied the electromagnetic interference shielding effectiveness properties of the 2024 alloy- fly ash composites. The composite have effective shielding property in the frequency range of $30.0 \mathrm{KHZ}-1.5 \mathrm{GHZ}$. But the addition of fly ash particulate decreases the tensile strength of the composites. Radhakrishna [23]: experimentally found that the wear resistance of $\mathrm{Al} \mathrm{MMC} \mathrm{increases} \mathrm{with} \mathrm{the}$ increase in fly ash content, but decreases with increase in normal load and sliding velocity, and also observed that the corrosion resistance decreases with the increase in fly ash content. 


\section{Titanium Dioxide Reinforce AMC}

Chaudhary et al. [24] : prepared $\mathrm{Al}-2 \mathrm{Mg}-11 \mathrm{TiO}_{2}$ composites through spray forming and stir casting technique and compared the frictional and wear behaviour of the composites. They observed the reduction in wear rate as compared to the base alloy when tested under the similar conditions. Higher micro hardness at the interface as compared to the matrix reflects good interfacial bonding. They also found that, addition of $\mathrm{TiO} 2$ particles in the alloy change the wear mechanism from purely adhesive to mixed mode of oxidative and abrasive wear. The size of the wear debris increased with the increase in load due to the increased size of the width of grooves. The pull out of $\mathrm{TiO}_{2}$ particles during wear caused abrasion on the matrix surface resulting in severe deformation of particles and platelets. The change from mild to severe wear was delayed in the composite as compared to the alloy with the increase of load. Hamid et al. [25]: prepared a light weight $\mathrm{TiO}_{2}$ reinforced composite by dispersing titanium dioxide $\left(\mathrm{TiO}_{2}\right)$ particles in the molten aluminium. The influence of both reinforcing particles and porosity contents on the wear and friction of in situ cast composites were evaluated. It was observed that wear rate and coefficient of friction of the in-situ cast composite decreased with the increasing load and the porosity content and also found to increase with the increasing the $\mathrm{TiO}_{2}$, content. Hemanth et al. [26]: used Taguchi technique for the simultaneous optimization of tribological parameters in metal matrix composite. Aluminium metal matrix composite (Al-Cu-Mg) alloy reinforced with $6 \mathrm{wt} \%$ of titanium dioxide was prepared using stir casting method. Dry sliding wear and frictional force of the composite material under different loads and sliding velocities revealed the improved wear behaviour of the composite. Sumanth H.R al [27]: investigated mechanical properties of Aluminum alloy (Al6061) with reinforcement of Titanium oxide. In this study the specimen by taking the different percentage of $\mathrm{TiO}_{2}$ as $(5 \%, 10 \%$ and $15 \%)$ in weight. From the experiment it is observed that for $5 \%$ of $\mathrm{TiO}_{2}$ reinforcement the hardness of the sample was maximum as compare to the other samples consequently the compressive strength is recommended for the $5 \% \quad \mathrm{TiO}_{2}$ metal matrix composite. Wear resistance increases with increase in percentage of $\mathrm{TiO}_{2}$ till $15 \%$. SEM test gives uniform distribution of reinforcement over the metal matrix.

\section{Boron Carbide Reinforced AMC}

Boyao et al. [28]: Investigated the trimodal aluminium metal matrix composites and the factors affecting its strength. The test result shows that the attributes like nano-scale dispersoids of $\mathrm{Al}_{2} \mathrm{O}_{3}$, crystalline and amorphous $\mathrm{AlN}$ and $\mathrm{Al}_{4} \mathrm{C}_{3}$, high dislocation densities in both $\mathrm{NC}-\mathrm{Al}$ and $\mathrm{CG}-\mathrm{Al}$ domains, interfaces between different constituents, and nitrogen concentration and distribution leads to increase in strength. Vogt et al. [29]: Studied the cryomilled aluminium alloy and boron carbide nano-composite plates made in three methods, (1) hot isostatic pressing (HIP) followed by high strain rate forging (HSRF), (2) HIP followed by two-step quasi-isostatic forging (QIF), and (3) three-step QIF. The test results showed that the HIP/HSRF plate exhibited higher strength with less ductility than the QIF plates, which had similar mechanical properties. The increased strength and reduced ductility of the HIP/ HSRF plate is attributed to the inhibition of dynamic recrystallization during the high strain rate forging procedure. Mahesh Babu et al. [30]: Investigated the characteristics of surface quality on machining hybrid aluminium- $\mathrm{B}_{4} \mathrm{C}-\mathrm{SiC}$ metal matrix composites using taguchi method. It was found that feed rate was the most important parameter followed by the cutting speed. Moreover it was concluded that the feed rate does not have a significant effect on surface quality.

Barbara Previtali et al. [31]: Investigated the effect of application of traditional investment casting process in aluminium metal matrix composites. Aluminium alloy reinforced with $\mathrm{SiC}$ and $\mathrm{B}_{4} \mathrm{C}$ were compared and the experiments showed the wear resistance of $\mathrm{SiC}$ reinforced MMC is higher than that of $\mathrm{B} 4 \mathrm{C}$ reinforced MMC. Uthaya kumar et al. [32]: Investigated the Coefficient of friction, Wear resistance. The $\mathrm{B}_{4} \mathrm{C}$ particles enhanced the production of rich tribo oxide layer by forming boron oxide which has reduced the progress of wear and coefficient of friction. At high loads and sliding velocities plastic deformation was the operating wear mechanism accompanied by the melt wear due to high order of local stress prevailing at the condition.

\section{Graphene Reinforced AMC}

The explanation of graphene covers all forms of graphitic material from $100 \mathrm{~nm}$ <thick platelets down to single layer graphene [33]. However, the obtain ability of single-or few-layer graphene that has caused the interest. Infact, it is possible to distinguish between flakes of graphene with different numbers of atomic layers in a transmission optical microscope 
due to its nature of significant optically energetic [34]. The work to determine the number of layers to be used for the reinforcement was formed and found that monolayer has the higher stress transfer than the bilayer graphene [35] and the flakes are sufficiently large(>30 micro meter ) and aspect ratio should be high for the effective reinforcement of both bilayer [36] and monolayer graphene in the composite [37]. There has already been considerable effort put into the development of way of preparing high-quality graphene in large quantities for the research purposes and also with the view to possible applications where it is suitable [38]. The very first attempt given to graphene preparation is break the graphite down into graphene by techniques known as a mechanical cleavage or liquid phase exfoliation. The other method chemical vapour deposition (CVD) is also used to synthesize graphene and in recent days thinner forms of graphite nanoplatelets (GNPs) [39] by differenttechniques known to be acid irradiation of graphite to microwave radiations, ball milling and ultrasonication. Fig.5 shows a molecular model of single atomic layer graphene sheet.

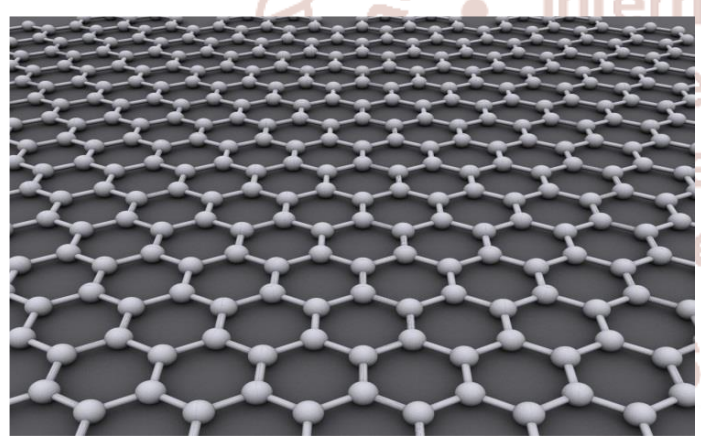

Fig.5 A molecular model of single atomic layer graphene

\section{Application of (MMC)}

Aluminium Matrix Composites (AMC) are used for fabrication of aeronautical and aerospace components, automotive parts (pistons, cylinders, head and block, chassis, connecting rods, brake components, clutches), brake rotors for high speed trains, bicycles, golf clubs, electronic substrates, cores for high voltage electrical cables, defence weapons, safety instrument ( Bullet proof jacket, Helmet, Bullets carrier).[40]

\section{CONCLUSION}

In this present review paper AMCs is manufactures by using stir casting technique. The variation of reinforcements with different content in composites composition Microstructure analyses and Mechanical properties, Density, Resistivity, Wear, hardness and tensile strength were studied.

$>$ With the increase of $\mathrm{SiC}$ and rice husk ash percentage hardness and porosity also increases but density decrease with increase in rice husk ash and $\mathrm{SiC}$ content the yield strength and ultimate tensile strength increases. The higher content of silicon carbide increased the porosity volume.

$>$ The addition of the $\mathrm{SiC}$ particulates improved the wear resistance by a factor of two in the mild wear region, and the transition temperature was raised by approx. $50^{\circ} \mathrm{C}$.

The maximum hardness was obtained at the peak aging $6 \mathrm{~h}$ of heat treatment and wear rate increased with increasing sliding speed and load. Addition of $\mathrm{SiC}$ particle increased the seizure pressure and temperature. The uniform distribution of $\mathrm{SiC}$ particles in aluminium alloy matrix was observed and the dendrites of $\mathrm{Al}$ and precipitates along the inter-dendritic regions were present.

The composites with high fly ash contents resulted in $13.6 \%$ less wear as compared to low fly ash content composites. More addition of fly ash contents tends to increase the coefficient of friction between the tribopairs. The reinforcement of particles has enhanced the tensile strength of aluminum matrix and composites From $173 \mathrm{MPa}$ to $213 \mathrm{Mpa}$.

The micro and macrohardness of the composites were increased from $69.53 \mathrm{HV}$ to $78.8 \mathrm{HV}$ and 49.4 $\mathrm{BHN}$ to 57.21 $\mathrm{BHN}$ with respect to addition of weight percentage of $\mathrm{SiC}$ and constant weight Percentage of FA particles. The SEM micrographs revealed the presence of $\mathrm{SiC}$ and FA particles in the composite with homogeneous dispersion.

The increase of fly ash content increased the matrix hardness which in turn enhanced the wear resistance of the composite as compared to the unreinforced alloy.

From the experiment it is observed that for $5 \%$ of $\mathrm{TiO}_{2}$ reinforcement the hardness of the sample was maximum as compare to the other samples consequently the compressive strength is recommended for the $5 \% \quad \mathrm{TiO}_{2}$ metal matrix composite. Wear resistance increases with increase in percentage of $\mathrm{TiO}_{2}$ till $15 \%$. SEM test gives uniform distribution of reinforcement over the metal matrix.

The wear resistance of SiC reinforced Al MMC is higher than B4C reinforced MMC. Graphene having important properties and have high levels of stiffness and strength, this means that the 
outcome of composite will possess outstanding mechanical properties.

Aluminium Matrix Composites (AMC) are used for fabrication of aeronautical and aerospace components, automotive parts (pistons, cylinders, head and block, chassis, connecting rods, brake components, clutches), brake rotors for high speed trains, bicycles, golf clubs, electronic substrates, cores for high voltage electrical cables, defence weapons, safety instrument ( Bullet proof jacket, Helmet, Bullets carrier).

\section{REFERENCES}

1. N. Wang, Z. Wang and G.C. Weatherly, "Formation of Magnesium Aluminate (spinel) in Cast SiC Particulate-Reinforced Al (A356) Metal Matrix Composites", Metall. Mater. Trans., 23 (1992) 1423-1431.

2. J. Hashim, L. Looney and M.S.J. Hashmi, "Metal matrix composites: production by the stir casting method", J. Mater. Process Technol. 92 (1999) 17.

3. Rao R N and Das S. "Effect of SiC content and sliding speed on the wear behaviour of aluminium matrix composites". Mater. Design. 32 (2011) 1066-1071.

4. K. Praveen Kumar, M. Gopi Krishna, J. Babu Rao, N.R.M.R. Bhargava, "Fabrication and characterization of 2024 aluminium - High entropy alloy composites" Journal of Alloys and Compounds 640 (2015) 421-427.

5. S. Rey, "Review Synthesis of Cast Metal Matrix Particulate Composites", J. Mater Sci., 28 (1993) 5397-5423.

6. M Gopi Krishna, K Praveen Kumar, M. Naga Swapna, J Babu Rao and NRMR Bhargava, "Metal-metal Composites-An Innovative Way for Multiple Strengthening" Materials Today: Proceedings 4 (2017) 8085-8095.

7. Uppada Rama Kanth, Putti Srinivasa Rao, Mallarapu Gopi Krishna, "Mechanical behaviour of fly ash/SiC particles reinforced Al-Zn alloybased metal matrix composites fabricated by stir casting method" j m a t e r r e s t e c h n o 1.201 $8 ; \mathbf{x} \mathbf{x}(\mathbf{x ~ x}): \mathrm{xxx}-\mathrm{xxx}$.

8. Gopi Krishna Mallarapu, Praveen Kumar Kancharla, J B Rao and N R M R Bhargava, "Mechanical behaviour of A356 alloy reinforced with high strength alloy particulate metallic composites" Mater. Res. Express 4 (2017) 086508 .

9. S.balasivanandha prabu, Karunamoorthy, S. Kathiresan, B. Mohan, Influence of stirring speed and Stirring time on distribution of particles in cast metal matrix composite. Journal of materials processing technology 171(2006) 268-273.

10. K.K. Alaneme, and A.O. Aluko, Production and age-hardening behaviour of borax pre-mixed $\mathrm{SiC}$ Reinforced. Al- Mg-Si alloy composites developed by double stir casting technique, West Indian Journal of Engineering,34(1-2),2012, 8085.

11. Dora Siva Prasad, Chintada Shoba, Nallu ramanainah, Investigations on mechanical properties of aluminium hybrid composite, mater res technol. 3(2014) 79-85.

12. D. Siva Prasad, C Shoba " Hybrid composites - a better choice for wear resistant materials", J Mater Res Technol, Volume 3 (2),2014,pp-172-178.

13. C. Neelima Devi, V. Mahesh and N. Selvaraj, "Mechanical characterization of Aluminium silicon carbide Composite", International journal of Applied Engineering Research, 1 (4), pp.793799, 2011.

14. Jasmi Hashim, "The production of cast metal matrix composite by a modified stir casting Method", Journal technology, Malaysia, pp 9-20, 2007.

15. M. Gopi Krishna, K. Praveen Kumar, J. Babu Rao , NRMR Bhargava , K. Vijaya Bhaskar, "Deformation Studies on A2024/Fly ash/Sic Hybrid Composites", International Journal of Engineering Research \& Technology (IJERT) ISSN: 2278 ,Vol. 2 Issue 10, October .

16. Johny James. S, Venkatesan. K, Kuppan. P, Ramanujam. R, "Hybrid Aluminium Metal Matrix Composite Reinforced With SiC and TiB2", Procedia Engineering 97 (2014) 1018 - 1026.

17. Viney Kumar, Rahul Dev Gupta, N K Batra, 2014, "Comparisons of Mechanical Properties and effect of sliding velocity on wear properties of $\mathrm{Al}$ 6061, Mg 4\%, Fly ash and $\mathrm{Al} 6061, \mathrm{Mg}$ 4\%,Graphite 4\%, Fly ash Hybrid Metal matrix composite", ELSEVIER,PP. 1365-1375.

18. Sumnath H R "Experimental investigation of mechanical and tribological behavior of Al6061$\mathrm{TiO} 2$ processed by powder metallurgy technique" 
IJSRD, Vol.3, Issue 03, 2015\ISSN (online): 2321-0613.

19. Vipin K. Sharma, R.C. Singh, Rajiv Chaudhary, "Effect of fly ash particles with aluminium melt on the wear of aluminium metal matrix composites", Engineering Science and Technology, an International Journal 20 (2017) 1318-1323.

20. Sandeep Kumar Ravesh, Dr. T. K. Garg. Prepration \& Analysis For Some Mechanical Property Of Aluminium Based Metal Matrix Composite Reinforced With Sic \& Fly Ash. International Journal of Engineering Research and Applications (IJERA) ISSN: 2248-9622 www.ijera.com Vol. 2, Issue 6, NovemberDecember 2012, pp.727-731.

21. S. K. Chaudhury, A. K. Singh, C.S. Sivarama krishnan, S. C. Panigrahi; "Wear and Friction Behavior of Spray Formed and Stir Cast Al-2Mg11TiO2 Composites", Wear, 258 (2005)759-767.

22. Abdulhaqq A. Hamid, P.K. Ghosh, S.C. Jain and Subrata Ray, "The influence of porosity and particles content on dry sliding wear of cast in situ $\mathrm{Al}(\mathrm{Ti})-\mathrm{Al}_{2} \mathrm{O}_{3}\left(\mathrm{TiO}_{2}\right)$ composite", Wear, 265 (2008) 14-26.

23. Hemanth Kumar. T.R., Swamy. R.P and Chandrasekhar T.K., "Taguchi Technique for the Simultaneous Optimization of Tribological Parameters in Metal Matrix Composite", J. Min. Mater. Charact. Engg. 10 (2011) 1179-1188.

24. Jang BZ, Zhamu A. Processing of nanographene platelets (NGPs) and NGP nanocomposites: a review. J Mater Sci 2008; 43:5092-101.

25. Blake P, Hill E W, Castro Neto A H, Novoselov K $\mathrm{S}$, Jiang $\mathrm{D}$, Yang $\mathrm{R}$, et al. Making graphene visible. Appl Phys Lett 2007; 91:063124.

26. Ali Mazahery and Mohsen Ostad Shabani, "Study on Microstructure and Abrasive Wear Behavior of Sintered Al Matrix Composites", Ceramics Inter., 38 (2012) 4263-4269.

27. Gong L, Young R J, Kinloch I A, Riaz I, Jalil R, Novoselov K S. Optimizing the reinforcement of polymer based nanocomposites by graphene. ACS Nano 2012; 6:2086-95.

28. Hernandez Y, Nicolosi V, Lotya M, Blighe FM, Sun ZY, De S, et al. High-yield production of graphene by Liquid-phase exfoliation of graphite. Nat Nanotechnol 2008; 3:563-8.
29. Rao CNR, Biswas K, Subrahmanyam KS, Govindaraj. A. Graphene, the new carbon. J Mater Chem 2009; 19:2457-69.

30. Jang B Z, Zhamu A. Processing of nanographene platelets (NGPs) and NGP nanocomposites: a review. J Mater Sci 2008; 43:5092-101.

31. Frank O, Bouša M, Riaz I, Jalil R, Novoselov KS, Tsoukleri G, et al. Phonon and structural changes in Deformed bernal stacked bilayer graphene. Lett 2012; 12:687-93.

32. G. Ranganath, S. C. Sharma and M. Krishna, "Dry sliding wear of garnet reinforced zinc / aluminium metal matrix composites", Wear, 251 (2001) 1408-1413.

33. S.C. Sharma, "The sliding wear behavior of Al6061-Garnet Particulate Composites", Wear, 249 (2001) 1036-1045.

34. Kumar, S., Sharma, V., Panwar, R. S., and Pandey, O. P., Wear behavior of dual particle size(DPS) zircon sand reinforced aluminum alloy, Tribol. Letts. 47 (2012) 231-251.

35. Martín, M. A. Martínez, J. Llorca, "Wear of SiCreinforced Al-matrix composites in the temperature range $20-200^{\circ} \mathrm{C}^{\prime \prime}, 193$ (1996) 169 179.

36. P. N. Bindumadhavan, Heng Keng Wah, O. Prabhakar; "Dual Particle Size (DPS) Composites: Effect on Wear and Mechanical Properties of Particulate Metal Matrix Composites", Wear, 248 (2001) 112-120.

37. M. Uthayakumar, S. Aravindan, K. Rajkumar; Wear performance of $\mathrm{Al}-\mathrm{SiC}-\mathrm{B} 4 \mathrm{C}$ hybrid composites under dry sliding conditions; Mater. \& Dsg, 47 (2013) 456-464.

38. Y.M. shivaparkash, K.V. Sreenivasa Prasad and Yadavalli Basavraj, "Dry Sliding Wear Characteristics of Fly Ash Reinforced AA2024 Based Stir Cast Composite", Inter. J. Current Engg. \& Technol., 3 (2013) 911-921.

39. M. Mahendra Boopathi, K.P. Arulshri and N. Iyandurai, "Evaluation of Mechanical Properties of Aluminium Alloy 2024 Reinforced with Silicon Carbide and Fly Ash Hybrid Metal Matrix Composites", American J. App. Sci., 10 (2013) 219-2295.

40. A. Sreenivsan, S. Paul Vizhian, N. D. Shivakumar. M. Muniraju, M. Raguraman, "A 
International Journal of Trend in Scientific Research and Development (IJTSRD) ISSN: 2456-6470

study of the microstructure and wear behaviour of TiB2 /Al metal matrix composites,' lajss. 8 (2011)1-8.

41. P.W Pawar and A utpat: Development of Aluminium based silicon carbide particulate metal matrix Composites for spur Gear, ICMPC (2014) procedia materials science (2014)1150-1156.

42. S. Kumar, "Effect of Reinforcement Size, and Volume Fraction on the Abrasive Wear of AA7075 Al/SiCp P/M composites-A Statistical Analysis", Tribol. Inter., 43 (2010) 414-422.

43. R.N. Rao and S. Das, "Effect of Applied Pressure on the Tribological Behaviour of SiCp Reinforced AA2024 Alloy", Tribol. Inter.,8 (2011) 454-462.

44. J. Rodriguez, P. Poza, M.A. Garrido and A. Rico, "Dry Sliding Wear Behaviour of Aluminium Lithium Alloys Reinforced with SiC Particles", Wear, 262 (2007) 292-300.

45. R.K. Uyyuru, M.K. Surappa and S. Brusethaug, "Tribological
Composites/Automobile Brake Pad System under Dry Sliding Conditions", Tribol. Inter. , 40 (2007) 365-373.

46. R.N. Rao and S. Das, "Effect of Heat Treatment on the Sliding Wear Behaviour of Aluminium Alloy (Al-Zn-Mg) Hard Particle Composite", Tribol. Inter. 43 (2010) 330-339.

47. M. Vanarotti, Synthesis and characterization of aluminium Alloy A356 and SiC Metal Matrix Composite, 2nd International conference on industrial technology and management, Singapore DOI: 10.7763/IPCSIT.2012.V49.3.

48. M.K. Surappa, Synthesis of fly ash particle reinforced A356 Al composites and their characterization, Materials Science and Engineering (A) 480, (2008), pp.117-124.

49. Rao VRK, Sarcar MMM. Tribological properties of aluminum metal matrix composites -AA7075 reinforced with titanium carbide (TiC) particles. Int J Adv Sci Technol 2016; 88:13-26.

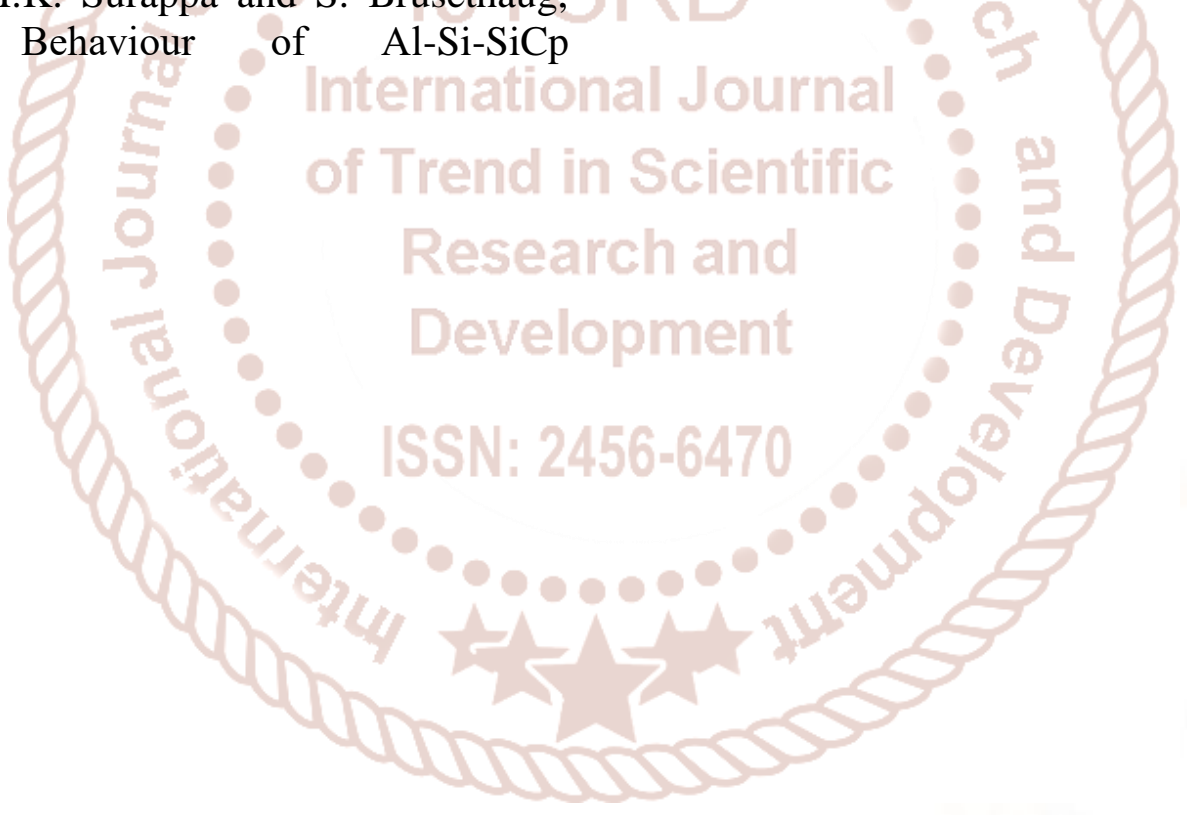

